\title{
TEM studies of in situ martensitic transformation in NiTi thin films
}

\author{
S. Crevoiserat, T. Lehnert, A. Hessler-Wyser and R. Gotthardt \\ École Polytechnique Fédérale de Lausanne, Département de Physique, IGA, PHB-Ecublens, \\ 1015 Lausanne, Switzerland
}

\begin{abstract}
Amorphous sputter-deposited Ti-rich NiTi thin films were annealed at different temperatures between $600^{\circ} \mathrm{C}$ and $900^{\circ} \mathrm{C}$ for $10 \mathrm{~min}$ to 3 hours inducing $\mathrm{Ti}_{2} \mathrm{Ni}$ precipitation. Differential scanning calorimetry (DSC) was performed on these specimens and their microstructure was investigated by transmission electron microscopy (TEM). In samples annealed at $600^{\circ} \mathrm{C}$ and $700^{\circ} \mathrm{C}$ for a short time, the DSC curves show, in addition to the $\mathrm{R}$ transformation, a multiple phase transformation with broad peaks. TEM observations reveal the presence of a great number of spherical $\mathrm{Ti}_{2} \mathrm{Ni}$ precipitates inside the grains and some larger precipitates at the grain boundaries. Annealing at higher temperature results in clear defined DSC peaks. The density of the precipitates inside the grains decreases while the number and the size of the precipitates at the grain boundaries increase. TEM studies of in-situ martensitic transformation showed that the distribution of the $\mathrm{Ti}_{2} \mathrm{Ni}$ precipitates strongly influences the martensitic transformation behaviour while the austenite/R-phase transformation is not affected. In samples with a large amount of precipitates inside the grains, a two-step transformation was observed : the martensite appears first along all the grain boundaries and then in the centre of the grains. This unusual feature of the martensitic transformation is considered to be responsible for the multiple transformation observed in the DSC curves.
\end{abstract}

\section{INTRODUCTION}

The study of sputter-deposited $\mathrm{Ni}-\mathrm{Ti}$ thin films is of great technological interest for applications in the field of microengineering. However, the shape memory behaviour of Ti-rich $\mathrm{Ni}$-Ti thin films has been reported to greatly depend on the annealing parameters, contrary to that of bulk specimens [1-4]. In the case of films the martensitic and reverse martensitic transformation temperatures were found to increase with increasing annealing temperature and/or time and the R-phase transformation can occur. This is considered to be due to a difference in the microstructure and particularly in the precipitate distribution between the films and the bulk material. After annealing thin films for a short time near the crystallisation temperature the martensitic and reverse martensitic transformation temperatures are highly depressed by the formation of coherent subnanometric Ti-rich plate precipitates which causes a strengthening of the austenitic matrix. These precipitates and their influence on the martensitic phase transformation (MPT) have been extensively studied by many authors [2, 5-6]. After annealing for longer time or at higher temperatures these plate shape precipitates do not appear any more but $\mathrm{Ti}_{2} \mathrm{Ni}$ spherical precipitates are formed within the NiTi grains. Further it was shown that such precipitate distribution was not stable against heat treatment [3]. Even if the influence of annealing parameters on the microstructure of Ti-rich $\mathrm{Ni}-\mathrm{Ti}$ thin films is relatively well known, the influence of the $\mathrm{Ti}_{2} \mathrm{Ni}$ precipitates on the MPT behaviour and the structure of the martensite itself are still not clear.

In the present article, the influence of $\mathrm{Ti}_{2} \mathrm{Ni}$ precipitates on the MPT is investigated by in-situ transmission electron microscopy (TEM) observations of the phase transformation. This study allowed to explain the peculiar features of the MPT displayed by differential scanning calorimetry (DSC). The evolution of the MPT behaviour could also be related to the microstructure of the corresponding films.

\section{EXPERIMENTAL PROCEDURES}

$\mathrm{Ni}-\mathrm{Ti}$ thin films were deposited on unheated glass substrates by if magnetron sputtering. The sputtering conditions are described elsewhere [7]. The amorphous as-deposited $8 \mu \mathrm{m}$ thick film was peeled from 
the substrate and cut into several pieces. For the DSC measurements, a film sample mass of $3 \mathrm{mg}$ was sufficient to obtain a good signal to noise ratio. Annealing was carried out in evacuated and Ar filled quartz-tubes followed by a water-quench. A first series of samples was heat treated for $30 \mathrm{~min}$ at $600^{\circ} \mathrm{C}$, $700^{\circ} \mathrm{C}, 750^{\circ} \mathrm{C}, 800^{\circ} \mathrm{C}$ and $900^{\circ} \mathrm{C}$ and a second one was annealed at $700^{\circ} \mathrm{C}$ for $10 \mathrm{~min}$ to 3 hours.

The film composition was determined to be 50.4 at.\% $\mathrm{Ti}$ by energy-dispersive $\mathrm{X}$-ray microanalysis in a Philips XL30 scanning electron microscope. Calibration was carried out with a Ni-Ti sample of known composition. In order to check the uniformity a $\mathrm{Ni}-\mathrm{Ti}$ film was deposited on a $\mathrm{Si} / \mathrm{SiO}_{2}$ substrate of typical size $\left(2 * 2 \mathrm{~cm}^{2}\right)$. For the composition measurements an automated and current stabilised electron microprobe was used. A maximum radial variation of $0.1 \pm 0.07$ at. $\% \mathrm{Ti}$ per $\mathrm{cm}$ was found.

Specimen for TEM studies were prepared by ion milling for several hours in a Gatan DuoMill. TEM observations were carried out in a Philips CM20 operated at $200 \mathrm{kV}$ using a double tilt specimen cooling and heating stage.

\section{RESULTS AND DISCUSSION}

\subsection{Differential Scanning Calorimetry}

The influence of annealing parameters on the properties of the MPT was first investigated by DSC. Figure 1 shows the DSC heating and cooling curves of the samples annealed at temperatures in the range of $600^{\circ} \mathrm{C}$ to $900^{\circ} \mathrm{C}$ for $30 \mathrm{~min}$. A complete thermal cycle was carried out before these DSC curves have been recorded. After annealing at $600^{\circ} \mathrm{C}$ and $700^{\circ} \mathrm{C}$, the DSC cooling and heating curves showed a wide-spread multiple transformation with several relatively weak peaks. Partial thermal cycles covering different temperature ranges between $-50^{\circ} \mathrm{C}$ and $100^{\circ} \mathrm{C}$ have been performed in order to clarify this transformation behaviour. This procedure allowed to identify the different transformation peaks in the DSC heating and cooling curves by measuring their corresponding transformation enthalpy. For instance, the peak labelled $R_{1}^{*}$ in the DSC heating curve of fig. 1 a) could be related to an $R$ phase/austenite transformation by cooling the sample annealed at $600^{\circ} \mathrm{C}$ from $100^{\circ} \mathrm{C}$ to $50^{\circ} \mathrm{C}$, i.e. a temperature just below the peak labelled $R_{1} / R_{2}$ in fig. 1 b) and by subsequently heating it to $100^{\circ} \mathrm{C}$. A more detailed analysis suggested that the samples annealed at $600^{\circ} \mathrm{C}$ and $700^{\circ} \mathrm{C}$ may contain two regions with different transformation behaviours. At $\mathrm{T}>80^{\circ} \mathrm{C}$ the whole film is in the $\mathrm{B} 2$ parent phase. Upon cooling, both zones transform first into $R$-phase at the same temperature, i.e $56^{\circ} \mathrm{C}$ (peak $R_{1} / R_{2}$ in fig. 1 b). However, both zones transform into martensite at different temperatures over a relatively wide range
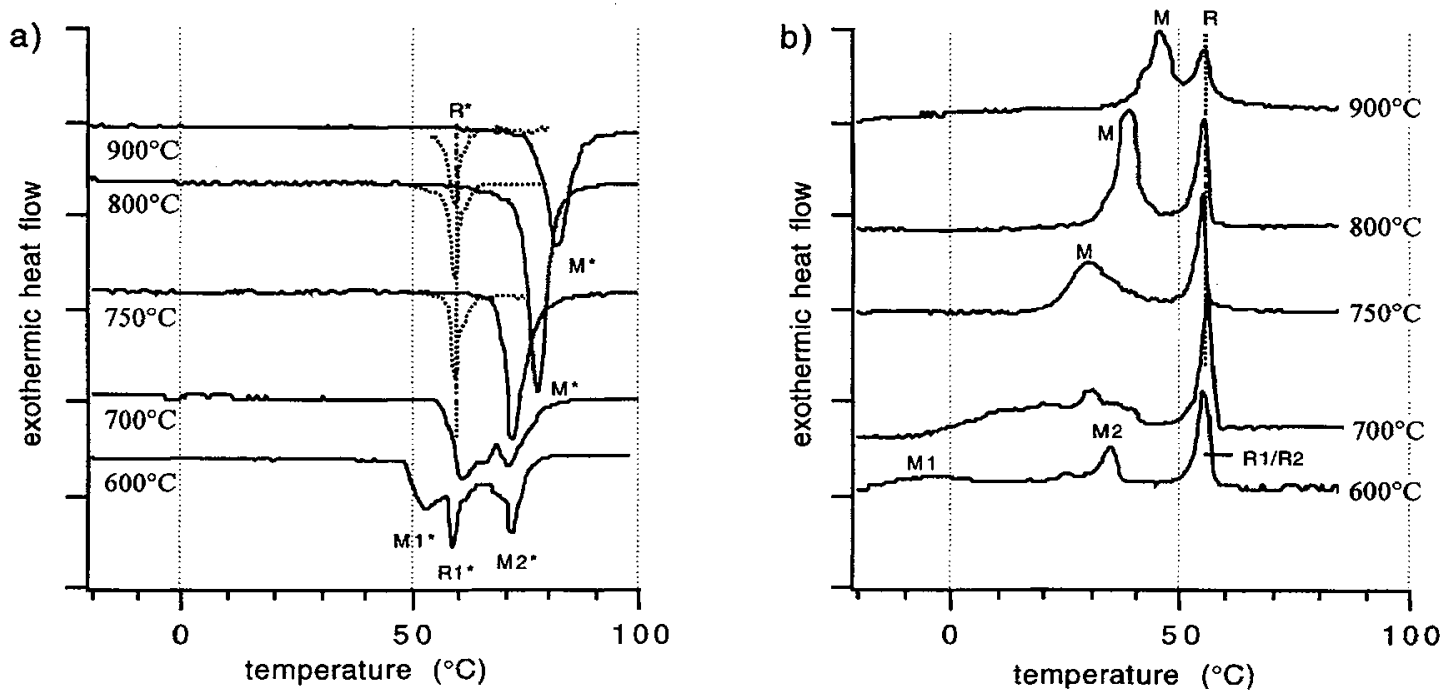

Figure 1: DSC heating (a) and cooling (b) curves as a function of annealing temperature ( $t=30 \mathrm{~min}$ ). 
(peak $\mathrm{M}_{2}$ and relative maximum $\mathrm{M}_{1}$ ). During heating, zone 1 shows a two-step reverse transformation from austenite into martensite via an R-phase (peaks $M_{1} *$ and $R_{1}^{*}$ in fig 1.a), while zone 2 retransforms directly from martensite into austenite at higher temperature (peak $\mathrm{M}_{2}{ }^{*}$ in fig. $1 \mathrm{a}$ ).

Annealing at temperatures in the range of $750^{\circ} \mathrm{C}$ to $900^{\circ} \mathrm{C}$ results in better defined transformation. A single martensite/B2 transformation peak $\mathrm{M}^{*}$ appears upon heating. The $\mathrm{R}^{*}$ peaks displayed in dashed line in fig. 1 a) and corresponding to an R-phase/austenite transformation could only be recorded after partial cycling. The $\mathrm{M}^{*}$ peak shifts towards higher temperature when the annealing temperature is increased. However two distinct peaks were still observed in the DSC curves upon cooling. The position of the first peak $\left(56 \pm 1^{\circ} \mathrm{C}\right)$ associated with the B2/R-phase transformation is independent of the annealing temperature. The second peak (labelled $\mathrm{M}$ ) corresponds to a "single" transformation of the R-phase into martensite. Different zones transforming at different temperatures do not appear any more. The $M$ peak becomes narrower when the temperature is raised from $750^{\circ} \mathrm{C}$ to $900^{\circ} \mathrm{C}$ and shifts by $+17^{\circ} \mathrm{C}$.

Investigations of the martensitic transformation in $\mathrm{Ni}$ - $\mathrm{Ti}$ thin films as a function of annealing temperature were carried out previously [1-2,4]. However a complex multiple transformation behaviour such as we observed in the temperature range up to $700^{\circ} \mathrm{C}$ was never reported. After annealing at higher temperatures, the evolution of the transformation temperatures is qualitatively comparable with that reported by other authors, i.e an increase of $M$ and $M^{*}$ while the $R$ peak is not affected. However we observed a transformation via an R-phase on cooling even at the highest annealing temperature.

The evolution of the transformation behaviour as a function of annealing time is very similar to that obtained by varying annealing temperature. The corresponding DSC curves are not shown, but only briefly discussed. After annealing for $10 \mathrm{~min}$ and $30 \mathrm{~min}$ several peaks appear in the DSC heating and cooling curves. They can be attributed to multiple martensite/austenite transformation via an R-phase as explained in the previous paragraph for the sample annealed at $600^{\circ} \mathrm{C} / 30 \mathrm{~min}$, where transformation peaks of two zones can be distinguished. Increasing the annealing time to $1 \mathrm{~h}$ and $3 \mathrm{~h}$ results in better defined peaks on the DSC curves. The transformation temperatures of the sample annealed at $700^{\circ} \mathrm{C}$ for 3 hours are almost the same as those obtained for the sample annealed at $800^{\circ} \mathrm{C}$ for $30 \mathrm{~min}$. A single martensite/austenite transformation peak is recorded upon heating, while two clearly defined peaks still appears upon cooling. All these peaks become sharper with increasing annealing time, but the position of their maximum does not significantly shift.

\subsection{TEM observations}

\subsubsection{Microstructure}

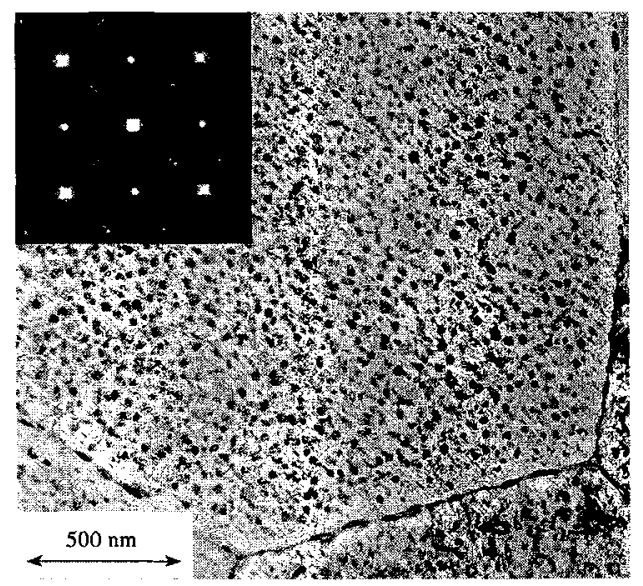

Figure 2: Film annealed at $600^{\circ} \mathrm{C}$ for $30 \mathrm{~min}$. The SADP corresponds to the superposition of [100]-type zone axes of the $\mathrm{B} 2$ phase and $\mathrm{Ti}_{2} \mathrm{Ni}$ particles with the same orientation.

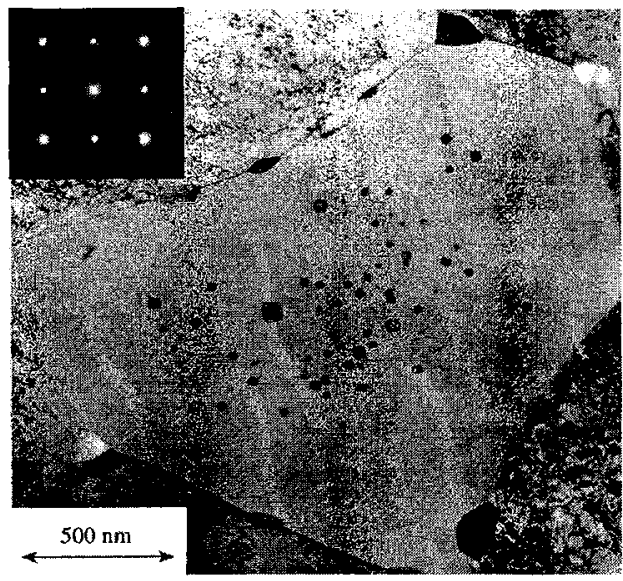

Figure 3: Film annealed at $900^{\circ} \mathrm{C}$ for $30 \mathrm{~min}$. The SADP corresponds to a B2 [100]-type zone axis. 
The study of the microstructure of the $\mathrm{Ni}-\mathrm{Ti}$ thin films as a function of annealing temperature and time were performed at $100^{\circ} \mathrm{C}$, so that all the samples were in the austenitic state. In the films annealed at $600^{\circ} \mathrm{C}$ for $30 \mathrm{~min}$ and $700^{\circ} \mathrm{C}$ for $10 \mathrm{~min}$ a rather non uniform bimodal grain size distribution with a typical size varying between 1.5 to $3.0 \mu \mathrm{m}$ and zones with somewhat larger grains in the range from 3 to $6 \mu \mathrm{m}$ is observed. After annealing at $700^{\circ} \mathrm{C}$ for $30 \mathrm{~min}$ and $1 \mathrm{~h}$ the average grain size is slightly reduced but the distribution is still non uniform (grain size in the range of 0.5 to $5 \mu \mathrm{m}$ ). With increasing annealing temperature or time the grain size ranges from 1 to $2.5 \mu \mathrm{m}$ and the distribution becomes more uniform. Grains with larger diameter do not appear any more in the sample annealed at $900^{\circ} \mathrm{C}$.

The evolution of the precipitate distribution as a function of annealing temperature was first investigated. Figure 2 shows a TEM micrograph of the film annealed at $600^{\circ} \mathrm{C}$ for $30 \mathrm{~min}$. A large amount of small round-shaped precipitates with a diameter of 10 to $30 \mathrm{~nm}$ can be seen in the interior of the grains. A small depleted zone with a maximum width of $50 \mathrm{~nm}$ is observed in the grains near the grain boundary. These spherical precipitates could be identified as $\mathrm{Ti}_{2} \mathrm{Ni}$. A typical selected area diffraction pattern (SADP) is shown in the inset of fig. 2. It could be interpreted as the superposition of the [111]-type zone axis of the $\mathrm{B} 2$ matrix and that of the $\mathrm{Ti}_{2} \mathrm{Ni}$ precipitates with the same orientation [6]. Some larger precipitates are also visible along the grain boundaries. No significant difference in precipitation distribution can be observed after annealing at $700^{\circ} \mathrm{C}$ for $30 \mathrm{~min}$. The density of the spherical $\mathrm{Ti}_{2} \mathrm{Ni}$ precipitates tends to decrease and the width of the depleted zone increases after annealing at $750^{\circ} \mathrm{C}$ and $800^{\circ} \mathrm{C}$ for $30 \mathrm{~min}$ while the size of the precipitates at the grain boundaries increases. A TEM micrograph of the sample annealed at $900^{\circ} \mathrm{C}$ for $30 \mathrm{~min}$ is shown in Figure 3. The amount of precipitates in the grains has strongly reduced. Moreover they are only observed in the central part of the grain. Their average diameter has slightly increased to about 30 to $50 \mathrm{~nm}$. The additional spots generated by $\mathrm{Ti}_{2} \mathrm{Ni}$ precipitates are now hardly visible in the diffraction pattern. The precipitates formed along the grain boundaries are much bigger compared to those observed in the samples annealed at lower temperatures. The typical size varies between 150 and $250 \mathrm{~nm}$, oval shaped ones may extend to a length of $400 \mathrm{~nm}$.

Figures 4 and 5 show bright field images and the corresponding diffraction patterns of the samples annealed at $700^{\circ} \mathrm{C}$ for $10 \mathrm{~min}$ and 3 hours respectively. The electron beam is parallel to [111 $]_{\mathrm{B} 2}$ in both cases. Comparing these two figures reveals that the amount of $\mathrm{Ti}_{2} \mathrm{Ni}$ precipitates decreases with increasing annealing time while their size distribution becomes more uniform. Moreover the average distance between two precipitates is about two times larger after annealing for $3 \mathrm{~h}$. The diffraction pattern generated by $\mathrm{Ti}_{2} \mathrm{Ni}$ particles became too weak to be detected.

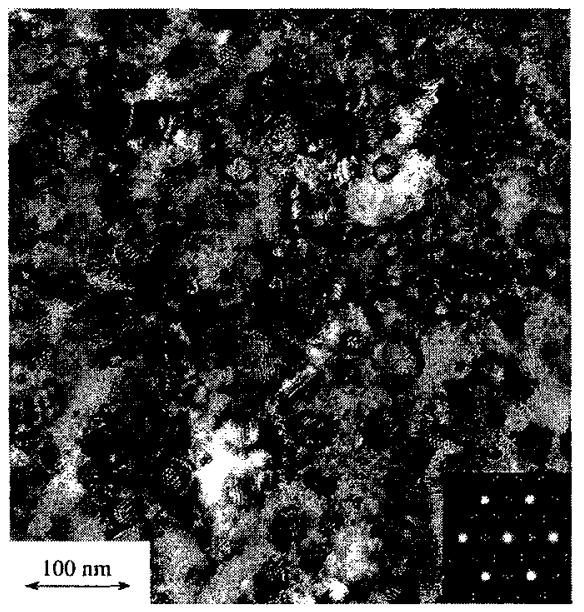

Figure 4: Bright field image of $\mathrm{Ti}_{2} \mathrm{Ni}$ precipitates in the film annealed at $700^{\circ} \mathrm{C}$ for $10 \mathrm{~min}$ and the corresponding diffraction pattern.

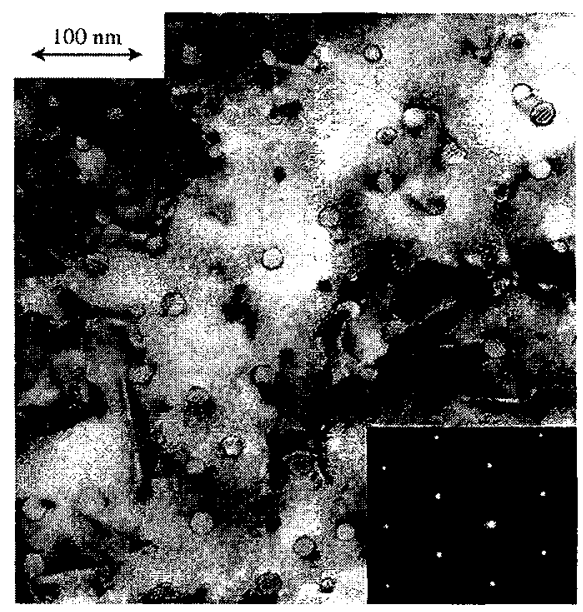

Figure 5: Bright field image of the $\mathrm{Ti}_{2} \mathrm{Ni}$ precipitates in the film annealed at $700^{\circ} \mathrm{C}$ for $3 \mathrm{~h}$ and the corresponding diffraction pattern. 


\subsubsection{Transformation behaviour}

In order to understand the evolution of the MPT measured by DSC and especially the origin of the multiple transformation recorded for the samples annealed at $600^{\circ} \mathrm{C}$ for $30 \mathrm{~min}$ and $700^{\circ} \mathrm{C}$ for $10 \mathrm{~min}$ and $30 \mathrm{~min}$, TEM in-situ observations have been performed. For that purpose, the samples were first cooled down from room temperature to $-50^{\circ} \mathrm{C}$. The MPT was then registered on a video tape while the temperature was increased up to $100^{\circ} \mathrm{C}$ and decreased to $-50^{\circ} \mathrm{C}$ again. Different parts of the same specimen were investigated. However the regions just near the edge could not be taken into account for this study because their thickness was not enough homogeneous. As a matter of fact it is known that the transformation temperatures are greatly depressed in very thin foils $(100 \mathrm{~nm})$ compared to those measured in the bulk [8]. Due to this dependence of transformation temperatures on thickness it was necessary to choose carefully the grains to be investigated to avoid that size effects warp the observations. Moreover it should be noticed that the absolute transformation temperatures measured in a TEM could therefore not be directly compared to those obtained with DSC.

The transformation behaviour observed upon cooling in specimens annealed at $600^{\circ} \mathrm{C} / 30 \mathrm{~min}$ and $700^{\circ} \mathrm{C}$ for $10 \mathrm{~min}$ and $30 \mathrm{~min}$, can be described as follow. At $\mathrm{T}=100^{\circ} \mathrm{C}$ the sample is in the $\mathrm{B} 2$ phase. The B2/R-phase transformation starts at $\mathrm{T}=56 \pm 1^{\circ} \mathrm{C}$ and is completed in the whole observed grain at $\mathrm{T}$ $=54 \pm 1^{\circ} \mathrm{C}$. On further cooling the martensite appears first along the grain boundaries. The temperature has to be lowered several degrees before all the grain boundaries are fully transformed. However no martensite could be seen yet in the centre of the grains. Figure 6 shows the film annealed at $700^{\circ} \mathrm{C}$ for 10 min during transformation. The picture was taken at $\mathrm{T}=1{ }^{\circ} \mathrm{C}$ while the first plates of martensite appeared at $10^{\circ} \mathrm{C}$. The martensite is clearly visible along the grain boundaries while the central part of the grains is still in R-phase. On further cooling the martensite starts to develop throughout the grains. At $\mathrm{T}=-9^{\circ} \mathrm{C}$ the observed region was fully transformed. The reverse transformation took place in a similar way. In the sample annealed at $700^{\circ} \mathrm{C}$ for $10 \mathrm{~min}$, the central part of the grains first transforms into R-phase between $\mathrm{T}=55^{\circ} \mathrm{C}$ and $58^{\circ} \mathrm{C}$. The martensite present along grain boundaries begins to shrink at $\mathrm{T}=64^{\circ} \mathrm{C}$ and disappears slowly on further heating. Between $\mathrm{T}=65^{\circ} \mathrm{C}$ and $67^{\circ} \mathrm{C}$, the centre of the grains transforms from R-phase into austenite, while some martensite can still be observed at the grain boundaries. These last martensite plates disappeared at $\mathrm{T}=69^{\circ} \mathrm{C}$ and transformed directly into austenite. The transformation behaviour is qualitatively the same in the samples annealed at $600^{\circ} \mathrm{C}$ and $700^{\circ} \mathrm{C}$ for $30 \mathrm{~min}$. In the latter however, these peculiar features of the MPT were not observed in the smallest grains. A transforming grain of the sample annealed at $700^{\circ} \mathrm{C} / 30 \mathrm{~min}$ and the corresponding diffraction patterns are shown in figure 7 . The SADP show that the central part of the grain is still in $\mathrm{R}$ phase while martensite is already present along grain boundaries. Comparing this figure to fig. 6 reveals that the region near the grain boundaries which transforms first into martensite is wider in this sample. It should also be noticed that the structure of the martensite itself is very complicated. The martensite plates are so small that it was not possible to acquire a diffraction pattern of a single variant.

These observations probably explain the "two-zone " feature observed for these samples in the DSC curves. In the first zone corresponding to the centre of the grains the matrix transforms via an R-phase during heating. Transformation temperatures $\mathrm{M} 1$ and $\mathrm{M} 1 *$ of this zone are lower than $\mathrm{M} 2$ and $\mathrm{M} 2 *$ in the second zone which corresponds to the region near the grain boundaries. A small depleted zone was observed in the samples annealed at $600^{\circ} \mathrm{C}$ for $30 \mathrm{~min}$ and $700^{\circ} \mathrm{C}$ for $10 \mathrm{~min}$. The width of this depleted zone increases with increasing annealing time or temperature. $\mathrm{Ti}_{2} \mathrm{Ni}$ particles in the interior of the grains seem therefore to hinder the propagation of martensitic plates and the martensite develops first in region free of precipitates. It was indeed shown that the interface between the $\mathrm{Ti}_{2} \mathrm{Ni}$ precipitates and the matrix phase was partially coherent [6]. These precipitates may therefore produce a strengthening of the matrix.

In the samples annealed at $700^{\circ} \mathrm{C}$ for $3 \mathrm{~h}$ and $800^{\circ} \mathrm{C}, 900^{\circ} \mathrm{C}$ for $30 \mathrm{~min}$. a more usual behaviour of the MPT was observed : the martensite grows very rapidly by bursts throughout the grains but not preferentially along grain boundaries. This is consistent with the microstructure of the corresponding samples where the amount of $\mathrm{Ti}_{2} \mathrm{Ni}$ precipitates within the grains has been shown to greatly decrease. The decrease of the average grain size observed in these samples may also play a role. Moreover the size of the martensite plates was found to increase. However further TEM study would be necessary to 


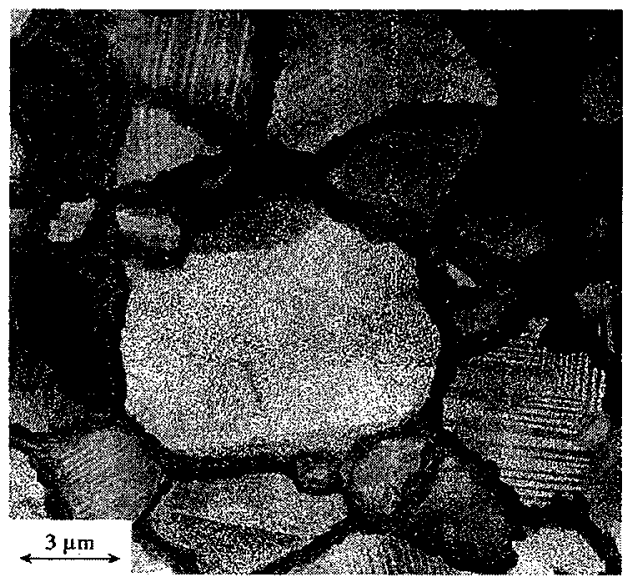

Figure 6: Bright field image of a film annealed at $700^{\circ} \mathrm{C}$ for 10 min during transformation from the $\mathrm{R}-$ phase into martensite.

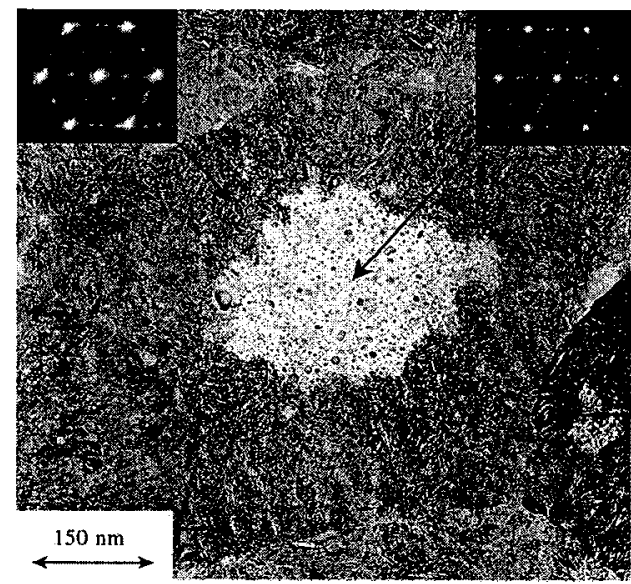

Figure 7: Bright field image of a transforming grain in a film annealed at $700^{\circ} \mathrm{C}$ for $30 \mathrm{~min}$ and the corresponding diffraction patterns.

clarify the influence of the $\mathrm{Ti}_{2} \mathrm{Ni}$ precipitates on the structure of the martensite itself.

\section{CONCLUSION}

TEM in-situ observations of the MPT showed that the distribution of $\mathrm{Ti}_{2} \mathrm{Ni}$ precipitates within the grains strongly influences the martensitic transformation behaviour of Ti-rich $\mathrm{Ni}$-Ti thin films, while the Rphase transformation is not affected. As outlined by means of DSC curves, two zones with different transformation behaviours can be distinguished in samples annealed at $600^{\circ} \mathrm{C}$ for $30 \mathrm{~min}$ and $700^{\circ} \mathrm{C}$ for $10 \mathrm{~min}$ and $30 \mathrm{~min}$. TEM investigation allowed to determine that the first zone corresponds to the region of the sample located near the grain boundaries, where the density of $\mathrm{Ti}_{2} \mathrm{Ni}$ precipitates is much lower. The second zone corresponds to the central part of the grain where the large amount of partially coherent $\mathrm{Ti}_{2} \mathrm{Ni}$ precipitates hinder the formation of the martensite plates. In this latter zone the martensitic and reverse martensitic transformation temperatues are therefore lower than those observed in the first zone. After annealing at higher temperatures or for longer time, the width of the depleted zone increases and the density of $\mathrm{Ti}_{2} \mathrm{Ni}$ particles decreases so that the strengthening effect vanishes. The whole grain can then transform into martensite at the same temperature.

\section{Acknowledgements}

The authors would like to thank Prof. F. Levy of the Institute of Applied Physics at the EPFL for placing his sputter deposition facilities at our disposal. This work was performed at CIME, EPFL with the financial support of the Swiss National Foundation for Scientific Research.

\section{References}

1. A. Ishida, M. Sato, A. Takei, S. Miyazaki, Mater. Trans. JIM 36, 1349 (1995).

2. Y. Nakata, T. Tadaki, H. Sakamoto, A. Tanaka, K. Shimizu, J. Phys. IV 5, C8-671 (1995).

3. Y. Kawamura, A. Gyobu, H. Horikawa, T. Saburi, J. Phys. IV 5, C8-683 (1995).

4. A. Gyobu, Y. Kawamura, H. Horikawa, T. Saburi, Mater. Trans. JIM 37, 697 (1996).

5. S. Kajiwara, T. Kikuchi, K. Ogawa, T. Matsunaga, S. Miyazaki, Philos. Mag. Lett. 74, 137 (1996).

6. A. Ishida, K. Ogawa, M. Sato, S. Miyazaki, Metal. Mat. Trans. A 28, 1985 (1997).

7. S. Crevoiserat, P. Scherrer, C. Dimitropoulos, R. Gotthardt, Mat. Sci. Eng. A 273-275, 357 (1999).

8. T. Kunimori, E. Sukedai, H. Hashimoto, Mater. Trans. JIM 37, 1404 (1996). 